\title{
COMPASSION-BASED MINDFULNESS TRAINING IN TEACHER EDUCATION: THE IMPACT ON STUDENT TEACHERS AT A SOUTH AFRICAN UNIVERSITY
}

\section{J. Draper-Clarke}

Drama for Life, School of the Arts

University of the Witwatersrand

Johannesburg, South Africa

e-mail: lucy.draper-clarke@wits.ac.za / lucyheartmind@gmail.com

\section{ABSTRACT}

This article presents findings from a teacher education study, exploring the implications of mindfulness training on student teachers in the context of a transitional society, South Africa. Western secular mindfulness has been expanding to new continents, from its origins in the East, and can now benefit from being contextualised. Recent critiques of the contemporary mindfulness movement identify elements that are missing from much secular mindfulness training, such as ethics, compassion, and social engagement.

As part of a mixed methods research study, in-depth interviews were carried out with fourteen student teachers in Gauteng, aiming to understand the level and causes of their stress, and evaluate whether a mindfulness-based intervention (MBI) was beneficial. The study's findings extended the current literature, highlighting the benefits of including compassion practices in MBIs, particularly in stressful contexts. Compassion-based mindfulness has the potential as a practice that not only improves the resilience of individuals, but also becomes a means of enhancing social engagement. For student teachers in the global south, mindfulness balanced with compassion impacted on their experience of self-compassion, empathy and compassion for others and altruistic behaviour. Explicit compassion training could, therefore, address some of the current critiques of MBIs.

Keywords: mindfulness, compassion, teacher education, higher education, stress, trauma, South Africa

\section{INTRODUCTION}

Western contemporary secular mindfulness was developed from Eastern contemplative practices, and has expanded rapidly over the last 40 years into new cultural contexts. Academic studies on mindfulness have reported promising results for the mind, the brain, the body and behaviour (Greeson 2009). In the education field, mindfulness-based interventions (MBIs) are being implemented successfully for students, student teachers, teachers and academics, and the field is rapidly gaining credibility (Meikeljohn et al. 2012; Jennings and Greenberg 2009; 
Roeser et al. 2012; Crain, Schonert-Reichl and Roeser 2016) as a means of addressing the contemporary challenges of education and society. In South African higher education too, researchers are exploring the need for academics to balance well-being with productivity, through mindfulness (Keane 2017). However, there is need for a critical evaluation of both its potential, and its potential pitfalls. There is concern that contemporary mindfulness has undergone "a make over in order to accommodate the needs of Western society deeply rooted in individualism, consumer capital, along with its pragmatic demands for tangible and worldly benefits" (Purser 2015). It is timely to evaluate whether MBIs, in their current form, are a suitable match for the cultural traditions and contemporary needs of South Africa, where higher education institutions are committed to decolonizing the curricula, in both its content and its pedagogy.

In a historically traumatised and socio-economically divided country such as South Africa, it is also valuable to examine the potential for mindfulness to support human flourishing. Its secular nature provides the opportunity to address stress and trauma, without alienating people from different cultural or religious traditions. It is necessary, though, to take critiques into account, and to ensure that MBIs address national concerns.

This article begins with the South African context, and then summarizes issues of contemporary mindfulness. It then reviews literature that points to the benefits of, and techniques for, integrating compassion practices, alongside mindfulness, into contexts of stress and trauma, with the intention of developing resilience and living consciously and pro-actively within a transitioning society. Qualitative findings from a larger mixed-methods research study are then analysed in the context of the compassion literature, to assess whether they point to useful conclusions for teacher education, in particular, and higher education, in general.

\section{BACKGROUND}

2014 marked the 20-year anniversary of political freedom in South Africa, yet it is still a country in transition. The "history of Apartheid state-sponsored violence and its struggle for liberation has contributed to what some refer to as a culture of violence" (Williams et al. 2007). Most South Africans have experienced at least one traumatic event in their lives, with resultant impacts on their mental health. The South African Stress and Health (SASH) Study (Herman et al. 2009) revealed that 30.3 per cent of the national population will suffer from mental illness during their lifetime, and students in higher education institutions seem particularly at risk (Waltham 2017).

Teachers, social workers and healthcare providers, "who work in traumatic environments often feel isolated, overworked, and powerless, thus increasing the possibility of being 
vicariously traumatized while offering services to communities that are victims of tragedy" (Berceli and Napoli 2007). Consequently, teacher education needs to be cognizant that many young teachers experience burnout, compassion fatigue (Marsay and Higson-Smith 2005) or become mentally ill themselves, and do not remain for long in the profession. Within the South African education system, stress-related diseases have been widely documented (Steyn and Kamper 2006; Paulse 2005; Saptoe 2000) and the attrition rate of teachers poses a serious threat to the educational system (Xaba 2003; DoE 2005; DoE 2007). Can secular mindfulness, in its current form, support the alleviation of some of these serious conditions?

Since the late 1970s, the teaching of Western secular mindfulness, and the associated academic research has expanded exponentially (Black 2013), primarily due to the work of Kabat-Zinn. He has provided evidence-based research on the effectiveness of MBIs in alleviating a wide range of physiological and psychological conditions attributed to stress (1994; 2003; 2005). The expanding evidence from neuroscience, particularly using fMRI scans, is validating what meditators have long experienced, namely that training the mind changes the brain and can reduce human suffering.

Despite the widely acclaimed benefits in the popular press, many researchers caution against the growing reputation of mindfulness as a "simple, general-purpose therapeutic technology" (Teasdale, Segal and Williams 2003). It also needs to be considered whether contemporary mindfulness programmes, designed for Western participants, will be of benefit in a society such as South Africa where Christianity is dominant and meditation is often viewed with suspicion (Groothuis 2004).

As the mindfulness movement gains momentum, both philosophical and practical questions are being asked about its uses (Purser and Loy 2013; Marx 2015; Monteiro, Musten and Compson 2015). The main philosophical concerns are that mindfulness has been extracted from broader Buddhist teachings, including ethics, and could be accused of producing a calm, unquestioning population, with a focus "on symptom reduction and improvements in psychosomatic well-being" (Purser 2015, 25). In contemporary capitalist societies, commentators are concerned that MBIs may be acting as a safety valve for addressing the stresses of modern life, rather than a means by which to investigate, and challenge, the underlying causes of those stresses, namely the ethics of trade, the expanding global inequalities and environmental devastation. In societies, such as South Africa, where natural resources have been extracted with little benefit to the general population, where human rights are often ignored, and where issues of social justice need to be addressed, it does not seem responsible to educate individuals to be calm but passive.

Some critiques seem to arise from the conceptualisation of mindfulness as having a single 
focus, that of attention in the present moment (Brown and Ryan 2003), or as "limited to dispassionate, emotionally cool, and metacognitive states of heightened mindfulness, contentless awareness and non-judgmental attention" (Loizzo 2014). Critics note that snipers can train their attention in the present moment to be more accurate killers, but is this really mindfulness? Other conceptualisations of mindfulness, particularly from Buddhism, are multifaceted including intentional and ethical components (Holmes 2010).

Kabat-Zinn defines mindfulness as "paying attention in a particular way; on purpose, in the present moment and non-judgmentally" $(1994,4)$. The term "non-judgmental" has resulted in some confusion, leading to a view of mindfulness as ethically neutral. Within Buddhism, a distinction is made between bare attention and mindfulness, and different traditions focus on contrasting aspects depending on the stage of a practitioner's training. Mahayana traditions conceptualize mindfulness ( $s a t i$ or smrti) as a practice of continually remembering underlying ethics, and choosing between helpful and harmful behaviours (Holmes 2010) adding an ethical dimension to the definition. Buddhism also distinguishes between right mindfulness and wrong mindfulness.

"The distinction is not moralistic: the issue is whether the quality of awareness is characterized by wholesome intentions and positive mental qualities that lead to human flourishing and optimal well-being for others as well as oneself" (Purser 2015).

Encouraging participants to bring non-judgmental acceptance to their inner world of thoughts, feeling and sensations, does not imply a passive acceptance of injustices that take place in the outer world. In fact, right mindfulness actively promotes behaviours that support eudaimonia, or human flourishing. Buddhism further differentiates between the beneficial state of calmabiding and meditation sickness where practitioners disengage from the world around them. Ethical passivity is considered a dangerous mental state (Sharf 2015).

Compassion, too, is often misunderstood, particularly when applied to the self. Compassion does not imply self-pity, nor does it equate with self-indulgence, self-centredness, selfishness or moral complacency (Neff 2015). Compassion is defined as being sensitive to the suffering of self and others, with the deep commitment to try to prevent and relieve it (Gyatso 2001a; Gilbert and Choden 2013), and compassion practices have been shown to assist in the cultivation of these qualities (Condon et al. 2013). The benefits of developing compassion are widely reported in Buddhist psychology, and are viewed as central to well-being (Davidson and Harrington 2002). Self-compassion as a construct is relatively new in Western psychological literature, yet is gaining prominence as an important mechanism for change.

The term "compassion fatigue" is widely used in the caring professions, yet also gives rise 
to misunderstanding. Young teachers may become burnt out by empathy - feeling the feelings of their students - while compassion has a protective element of engagement that is able to prevent burnout by creating feelings of well-being, connection and efficacy (Neff 2015; Klimecki et al. 2012).

Contextualising mindfulness training involves taking the existing socio-economic and cultural conditions into account. The arrival of mindfulness in South Africa has provided an opportunity to consider the needs of a post-conflict society, and make meaningful decisions on how to take the field forward. The literature on MBIs suggests that it has the potential to enhance resilience and sustainability in supporting professionals that deal head on with social issues of violence and trauma.

For human service professionals to address the widespread challenges of social inequalities and suffering, without burning out or experiencing empathy fatigue, it seems important to combine the therapeutic benefits of compassion-based mindfulness, which allow for the cultivation of a calm, non-judgmental mind state, with the outward-moving commitment to mitigate what Purser and Loy call "the causes of collective and organizational distress" (2013).

\section{LITERATURE REVIEW}

Nussbaum describes compassion as "the bedrock of the ethical life" in terms of individual wellbeing and institutional design for improving public life (2003), and other writers portray compassion as the foundation of secular ethics (Ozawa-de Silva et al. 2012; Gyatso 2001b) in order to allow for all life on earth to thrive. Compassion's important role in the flourishing of self and other, and as the foundation of altruism and secular ethics, are explored below to frame, and maybe offer answers, to some of the critiques of secular MBIs.

Ancient and contemporary literature presents compassion as both an evolutionary necessity and a valuable human capacity. It is most commonly defined as an other-oriented emotion however recent work on self-compassion is also gaining prominence in the literature. Compassion is viewed as an innate capacity, linked to empathy, and also as a potential that can be cultivated through practice, even in adulthood, due to the brain's neuroplasticity. This means that it can both manifest as a momentary state, and be developed as a stable personality trait.

For mammals in particular, whose young cannot survive without care, compassion is a necessity for their survival (Wright 2010; Armstrong 2011). Similarly, in terms of the survival of groups, compassion strengthens social connection (Ozawa-de Silva et al. 2012; Seppala, Rossomando and Doty 2013). However, the evolutionary orientation rarely extends compassion beyond the in-group. This narrow focus has revealed itself as in-group bias, which can even 
result in competition and aggression towards out-group members (Sherif et al. 1961). The ingroup is deemed more worthy of compassion than the out-group.

Other interpretations view compassion as a far-reaching human capacity, which can be offered to both human and non-human beings as well as the environment (Nussbaum 2003; Gyatso 2001a). Nussbaum cites the ancient Greek philosopher, Hierocles, who talked of people's ability to draw widening circles of compassion in towards the centre, as they develop morally. Buddhist perspectives on compassion align with this broad-reaching conceptualization, and emphasize the importance of regular training in compassion (Salzberg and Kabat-Zinn 2004) in order to enhance this process of moral development. In recent years, these theories have been tested through neuroscience research (Singer and Klimecki 2014; Klimecki et al. 2012).

Contemporary research studies using neuroimaging techniques with wait-list and active control groups have revealed that compassion practices are capable of changing the brain, and consequently the behaviour of practitioners, resulting in greater real-world altruism (Condon et al. 2013; Weng et al. 2013). The altruism study of Weng et al. provided evidence that compassion training can increase altruistic behaviour, which seems to "emerge from increased engagement in neural systems implicated in understanding the suffering of others, executive and emotional control and reward processing" $(2013,1171)$. This in turn increases the reward value of helping those who are suffering. The researchers concluded,

"Compassion and altruism can be viewed as trainable skills rather than stable traits. This lays groundwork for future research to explore whether compassion-related trainings can benefit fields that depend on altruism and cooperation" $(2013,1178)$.

Klimecki et al.'s (2012) study revealed that compassion provides a protective buffer for those engaged in emotionally demanding work. Their study suggested that compassion training actually enhanced positive emotions and feelings of affiliation. Before training, participants' response to the suffering of others was activated in the neural networks underlying empathy for pain. After compassion training, participants experienced activity in the neural networks linked to positive affect and affiliation. "These findings suggest that the deliberate cultivation of compassion offers a new coping strategy that fosters positive affect even when confronted with the distress of others" $(2012,1)$.

Weng et al. (2013), and Klimecki et al.'s (2012) conclusions point to the potential benefit for students within higher education, who may be considering human service professions, in terms of developing resilience, and compassionate personality traits. How, though, can this training in compassion take place? 
In exploring the arising of compassion, I have identified five distinct stages that are discussed by researchers including Strauss et al. (2016), Gilbert and Choden (2013) and Goetz, Keltner and Simon-Thomas (2010). These are:

1) Sensitivity towards, and recognition of, another's pain or difficulty;

2) Emotional connection with the one suffering, through empathy;

3) Tolerating uncomfortable feelings/physical sensations aroused in response to the one suffering, so that we remain open to and accepting of those feelings;

4) Understanding that physical or emotional pain is a universal experience of all sentient beings;

5) Acting to alleviate the suffering through presence, kind speech or skilful action, depending on the underlying causes, and on what is most beneficial for the one suffering.

The stages can be abbreviated to Recognize, Empathize, Bear, Understand, and Alleviate, and an investigation into these interconnected stages is useful for categorizing types of training, and evaluating its effectiveness. The contemplative traditions have long claimed that compassion can be enhanced with specific meditation techniques, which serve to counteract self-centred tendencies (Lutz et al. 2008).

\section{Recognize}

Recognition, through sensitivity, can effectively be taught during mindfulness practices, which require attention to be directed to the present moment, whatever is occurring. Interestingly, early Mindfulness-based Stress Reduction (MBSR) training did not include explicit compassion practices as Kabat-Zinn asserted that compassion would naturally emerge, as it is an innate human quality. He experienced that compassion was co-created in a group, as long as it was embodied by the teacher. This view has been supported in some research studies (Condon et al. 2013; Feldman and Kuyken 2013). However, Mahayana Buddhist psychology clarifies that mindfulness is a vital pre-requisite for compassion, but the quality still needs to be cultivated in order to extend compassion beyond the individual's closest social circles.

\section{Empathize}

The next step, empathy, can be developed in many ways. Nussbaum advocates strongly that empathy is cultivated through the arts and humanities as they familiarize people with "the diversity of circumstances in which human beings struggle to flourish" $(2003,432)$. Witnessing others' suffering in theatre productions or novels cultivates the ability to imagine their life- 
worlds, and therefore allows the development of empathy. Empathy is an extremely useful skill, but may also result in burnout, as has been documented in professions such as nursing and teaching (Marsay and Higson-Smith 2005). Neff (2015) explains this process as one of empathic resonance: witnessing suffering in others activates the pain centres in our own brains. This can result in empathy fatigue, particularly when caregivers experience vicarious trauma (Berceli and Napoli 2007). This is why compassion training is necessary to allow for the development of skills beyond the stage of empathy.

\section{Bear}

Tolerating discomfort, or bearing witness to pain (one's own or another's), is counterintuitive from an evolutionary perspective, as the brain's ancient survival system is hard-wired to move animals away from pain or danger. However, when painful experiences are caused by unprocessed traumatic experiences, it is necessary to integrate them. Traumatic experiences tend to sensitize people into becoming overly reliant on processing from their threat systems (Gilbert and Tirch 2009). Gilbert and Proctor reveal that, "patients with chronic difficulties, especially those from traumatic backgrounds, who may lack a sense of inner warmth or abilities to be self-soothing" $(2006,353)$ can benefit from compassion training. Compassionate attention is the key to the healing process and a significant mechanism of change (Gilbert 2010).

Through mindfulness practices and/or therapy, people become increasingly aware of their habitual tendencies, shifting the locus of responsibility from the external to their internal world. When facing negative patterns, this can be a challenging shift. Gilbert has researched evolutionary approaches to psychopathology, particularly shame and depression, concluding that compassion is the basis of courage and transformation. Based on his research, Gilbert (2010) created an evolutionary model of social mentality theory, where he describes three major Emotion Regulating Systems in the brain: the threat and self-protection system; the incentive and resource-seeking system; and the soothing and contentment system. Health and well-being develop through accepting the evolutionary necessity, and the conscious balancing, of these three systems. In a country where the majority of residents have experienced traumatic incidents (Roe-Berning 2009), and their threat-focused system is a key determinant of behaviour, learning self-compassion could be a key life skill. Literature from clinical psychology has grown the field in regard to self-compassion as a therapeutic technology for healing, as well as the pro-social aspects vital for enhancing relationships in the caring professions (Neff 2003; Gilbert 2010). 


\section{Understand}

Understanding that all beings suffer, and experience the 10,000 joys and 10,000 sorrows of a human life (Kornfield 2009) is taught in Buddhist practices through the cultivation of equanimity (DesBordes et al. 2015). It is a universal experience that Neff (2003) calls common humanity, and is an integral aspect of her work on self-compassion. She highlights selfcompassion as a construct that includes self-kindness, common humanity and mindfulness, which stand in contrast to their counterparts of self-criticism, isolation and over-identification.

"While mindfulness trains participants to be experientially open to their own suffering without being caught up in it, self-compassion allows for a sense of accepting the experiencer, with warmth and tenderness, particularly when an experience is painful" (Neff 2015).

Understanding the universal nature of suffering not only allows individuals to find compassion for their own difficulties, but also supports them in bearing witness for others, knowing that they will usually be able to build their own resources for coping and cultivating resilience for future challenges.

\section{Alleviate}

The final step, of alleviating suffering, can be taught as simply giving compassionate presence, or kind thoughts (in the form of wishes or prayers). In addition, in therapeutic settings particularly, Western psychology emphasizes the use of skilful speech. Another way to alleviate suffering is through action - for the individual who is suffering, or through activism - for the community who is being harmed. Whether alleviation is offered through thought, word or deed, the proactive, engaged, pro-social characteristics have been the focus of recent neuroscience research, due to their link with human well-being.

\section{Compassion practices}

Training in compassion practices aims to cultivate affective emotions, such as friendliness, kindness and compassion, in relationship to oneself and others, even those not known personally. This has a dual benefit, of providing experience of these practices at times of intraor interpersonal difficulty as well as, in the longer term, developing pro-social qualities as personality traits, resulting in more consistent altruistic behaviour towards others.

Commonly taught practices in secular settings include Loving Kindness, the SelfCompassion Break and RAIN practice. In Buddhist retreat settings, Tonglen meditation taking in suffering and offering compassion (Chödrön 2001) or Chöd - feeding your demons (Allione 2008) are also taught, but these do not form part of secular 8-week courses. Loving 
kindness practices include sending wishes of care and compassion to oneself and to others, by using a set of repeated phrases, "May I/you be happy, safe, well and live with ease" (Salzberg and Kabat-Zinn 2004). The Self-Compassion Break, a set of three repeated phrases, invites participants to attend to difficulties with mindfulness, a sense of shared common humanity and self-kindness (Neff and Germer 2013). The RAIN practice is an acronym for Recognising difficulties, allowing them to be experienced, then Investigating the physical sensations of the body, emotional experiences, and the co-emerging thought patterns. Once the investigation has been carried out, without a wish to try and fix or get rid of the experience, then the practitioner moves to a stage of Nurturing, or Non-identification, where the situation is seen within its broader context (Brach 2013).

In terms of the compassion literature's application to teacher education and higher education, three dimensions of compassion emerge: self-compassion at times of personal difficulty, which serves to prevent the teacher or care-giver from projecting their own suffering onto the people in their care. Compassion also co-arises with empathy, which serves as a protective buffer for teachers working in conditions where they experience their students' suffering. Finally, compassion is shown to result in altruistic behaviour, which is the opportunity for teachers to play not just an educational, but also a pastoral role in the lives of their students. In addition, they may also begin to play an activist role, if they see that structural conditions are impacting the well-being of their students.

\section{METHOD}

Qualitative data was gathered as part of a larger mixed methods research study. Fourteen racially diverse student teachers enrolled in the Post Graduate Certificate in Education (PGCE), attended in-depth interviews before and after the MBI. The PGCE is a one-year course designed to prepare graduates for teaching in schools, and is recognized worldwide as a high-stress life stage (Kyriacou 2011). The mean age of the students was 25 years, and they drew from different ethnic and cultural backgrounds (Draper-Clarke and Edwards 2016). The study was in accordance with the ethical standards required by the University of the Witwatersrand (Wits) and covered informed consent, confidentiality assurance and disclosure risks.

Contemporary research claims reinforced my conviction that compassion is a necessary aspect of mindfulness practice and a key mechanism of change, and that relevant practices should therefore be incorporated explicitly, rather than implicitly into MBIs.

The intervention was adapted from the Mindfulness Based Living Course (MBLC) (Nairn 2009) and condensed into six weeks to meet the availability of students between their two periods of teaching experience (TE). The curriculum content of this MBI is informed by the 
work of Kabat-Zinn (2005), Neff and Germer (2013), Gilbert (2010), and Mahayana Buddhist psychology (Holmes 2010). This course was chosen as it includes four explicit compassion practices alongside mindfulness meditations: the Felt Sense of Kindness, the Self-Compassion Break, RAIN and Loving Kindness.

\section{QUALITATIVE FINDINGS}

A thematic analysis of the interviews showed consistency with the literature. The findings are therefore categorised into 1) self-compassion, 2) empathy for the difficulties of others, and 3) altruistic behaviour. The findings were reported both in relation to the student teachers' personal and professional lives.

\section{Self-compassion}

In the first interview, Luthuli, a black male student, said: "I am a perfectionist. So far I have not forgiven myself because I feel I still need to fix certain things. During my undergrad years, the ganja affected my schoolwork. My marks dropped. I can only forgive myself after I have redone everything. My aim is to get a distinction for PGCE this year, and I can start forgiving myself as I will have corrected my mistakes." In subsequent interviews he described the selfcompassion practices as "transformational". He was coping with financial hardship, recovering from addiction, and holding extremely high expectations of himself, realising during the SelfCompassion Break, that, "The emotions were in my mind, but when I was giving myself the hug, it felt maybe I needed someone to hug me. It felt supportive." He further reported, "I was trying to be kind to myself, and then stop trying to find a way to solve the problem. You don't have to pre-empt what's going to happen. Be kind to myself, not try to figure out or trouble shoot. For me, I tried not to build a story in my mind." The MBLC helped him to understand the difference between authentic pain and adventitious mental proliferation, and he described being able to let go of a stream of secondary stories, allowing him to focus more kindly on the genuinely painful experiences that he was dealing with.

Georgia, a white female student, also identified herself as a perfectionist in her preliminary interview: 'I'm a perfectionist and I won't let things go until they are $100 \%$ in my mind. I'm not happy if it's anything less than the best. I put pressure on myself." During one practice she noted physical sensations and a release of tension: "I think of a glow, almost like a golden colour. I feel warm inside and happy and a huge grin. I love the hugging sensation; I think that works and that felt good. Then I felt something in my heart. It felt a bit sore, not sore, but I could feel it, and then after a while, it felt warm, a bit of a release."

Despite high expectations of herself, she was able to change her striving behaviour: "I 
realize how beneficial it is now to take time off for yourself, which I never did previously. I was always sort of over-motivated and over-striving, and burn myself out in doing so. Now I feel I am strong enough, I can write my essays, and I know that if I do everything one on top of the other then my standard of work lowers ... there's more to life than just getting straight As. You have to nurture yourself as well and what you want to do in life, and what makes you happy."

When Hannah (white, female) first experienced the Felt Sense of Kindness practice, she reported: "It was very difficult. Not so hard to think about a memory when someone was kind to me, but a little bit more difficult to think about when I was kind to someone else." The following week, she said, "I tried to do the kindness practice again, but I find it extremely difficult as a lot of feelings of guilt come out of it. I could be more kind to myself, to other people, there are people far worse off than me." She recalled, "I've been brought up, not by my family, but through my studying and stuff, at Drama school you were not allowed to miss if you are sick, you push through, even if you are dying, you go to rehearsal, which is not healthy. So I struggle with taking time off due to ill health, then the guilt comes in and you miss all the work, so I generally try to push through things ... being kind to myself is something that I don't do. I worry so much about others." This guilt and pressure resulted in clinically high scores on the Depression, Anxiety, Stress Scale (Draper-Clarke and Edwards, 2016) and she spoke of fears that "I will end up killing myself." These were eased significantly during the intervention. She gave herself permission to go on holiday, "I went away for 10 days, and I didn't take any work with me ... that really helped with my mind frame before I came back."

Richard (white male) was initially sceptical of the construct and stated how he is "wary of self-compassion as it can become an excuse, be careful about how much leeway you give yourself. I think there's a very fine line between self-compassion and making excuses for yourself." However, after first experiencing the RAIN practice, he noted an important distinction between a person's behaviour and the person as a human being. He was able to forgive himself for unskilful behaviour: "I realized that I had done a bad thing, but that I am not a bad person."

Kim (Chinese South African, female) also found the self-compassion break supportive at times of difficulty, and felt that she was able to stay open to uncomfortable feelings, without trying to suppress the problem. In the early stages of the training, she identified the complexity of feeling an expectation towards helping others, as a result of her conditioning, without the grounding in self-compassion. She had felt an obligation to be kind to someone, which did not feel authentic, "I was very irritated with this colleague of mine, who needed help, and instead of not doing anything, I helped her, but I felt heavier and upset as I realized by helping her, I 
was not helping myself." Later on, after learning the self-compassion practice, she reported, "When you acknowledge it, it felt lighter, like everything is going away. There's no resolution, like what should I do to the situation to solve it, but it makes you feel lighter. There's a sense that there may be a solution some day."

Nicholas (black, male) mentioned that the compassion element was particularly beneficial for him at moments of stress in reducing his self-critical voice. He was able to connect with the universal nature of suffering: "I'm not too judgmental on myself as I used to. I will do something and I will just realize that it happens as part of life, but I wouldn't say, 'I shouldn't be doing this, shouldn't be doing that.' [My critical voice] is less powerful."'

The self-compassion practices benefited a number of students who prioritized self-care, so that they did not give from a place of depletion. The sense of well-being revealed itself at a physical level, with feelings of warmth and relaxation in the body as well as spontaneous smiling; the emotional level, with feelings of calmness, lightness and happiness; and the mental level, with an understanding that a solution to the presenting difficulty may arise in its own time. In addition, students noticed that by offering self-kindness at the time of suffering, they were able to prevent mental proliferation.

\section{Empathy for the difficulties of others}

Atandwa, who had coped with challenging childhood circumstances when she was abandoned by her mother and moved from relative to relative, experienced fewer feelings of judgement towards herself, and also towards her family members who had acted in hurtful and unskilful ways. She realised that their behaviour was a result of their suffering and was able to acknowledge that they are fallible humans. She forgave many of the incidents from the past, with a remarkable quality of acceptance. "My relationship with my Mum, we are growing in a way ... Like when I go out, I text her and let her know, and she appreciates things like that."

Georgia spoke about her insight that all humans experienced suffering. She was very upset about the behaviour of the students in her TE school, "These people are disgusting, and they don't understand me and I'm trying so hard". She then realised that she did not need to take things so personally and was able to think "more deeply about where the other person was coming from, and what situations they were going through and why they were acting the way they were". She concluded, "Thinking about other people's feelings and emotions and what's making them act the way they are helped a lot this time around, instead of just getting upset and taking everything personally. They're just human, they are also going through their own things." She could discuss issues empathetically with the students, "I can accept that you are feeling upset about this or that, but you still have to do your work, you can't just slack off ... if 
you guys want to get to university, you have to do this."

Georgia also found herself responding to a situation in an unexpected way: "I was quite proud of myself that I kept it together. I was [thinking] 'they are people too and make mistakes' so it calmed me down before I wrote a scathing email."

Luthuli spoke about discovering the background of a disruptive learner, and how his attitude and behaviour towards him changed instantly, allowing Luthuli to connect with him in a meaningful way. "After I learnt the situation of the young boy, his parents were killed in front of him, I think it created a shift in my mind, the way I was looking at him. I was no longer looking at him as a disruptive learner, but I was looking at him as someone who is suffering. [...] The second day, when they were leaving, I called him to stay behind and I went and told him that he should be careful with his friends, most of his friends have parents and everything, his situation might be different in other ways. I also said, "I have heard from the teacher that you are a very intelligent boy and you do well every time if you focus on your work, so maybe it is something that you should start doing". And on the third meeting, he submitted one of his works that he had not submitted for a long time.

Sipho and Luthuli's experience with their colleagues during teaching experience was challenging. They had hoped for support from the experienced staff, but instead found them to be unfriendly, and sometimes even obstructive. Luthuli noted, "I think there are many reasons, but one of the reasons is becoming successful at a young age, while during their time, because of the conditions during their times, they could not be successful at our age. I think this is one big problem. Two, they get threatened that maybe we are coming to take their positions and maybe they'll be left with nothing." He addressed their unfriendliness "by just trying to be compassionate".

Bonolo spoke of his increasing openness towards other students, particularly with regard to race. He had assumed that white students would not want to talk to him due to "the history of this country" and "because of how I dress" (in "typical township style"), but found that he started to talk about "real issues" and "we went deep". "I thought this guy was one privileged white guy like any other white person who always thinks about himself, you know, doesn't care about township lifestyle ... so that's where I realized that, you know what, the more you talk to people, the more you'll get to know them." "There are people whom I never spoke to, but after mindfulness I saw myself making conversation with people I'd hardly spoken to. It's not just the kindness. Even if our relationship is formal, you are still a human being ... I think, maybe in terms of my social life and personal life, it encouraged me to be an open person, to talk more."

The student teachers seemed to improve their levels of empathy and compassion, and 
became more understanding with regard to the struggles of others, whether family members, school pupils, colleagues across the race divide, or their supervisors. This allowed for increasing levels of understanding regarding the behaviour of others, and improvements in their own reactive behaviour.

\section{Altruistic behaviour}

Atandwa found herself responding altruistically to a request for volunteers after the compassion practices. She also had the insight that kindness to others actually resulted in her own happiness: "I find myself eager to do more things. Like now I joined this volunteer thing where we teach kids. And before [the training], the first thing I'd think about was, 'How much are they going to pay us?' And there's no money, they're just giving us R100 for transport, but that was not the first thing on my mind. So, like being kind to other people, you know ... The volunteering thing, it's great, it's an experience. It's something I can even put on my CV ... So being kind has actually been kind back to me!"

Imogen noticed how her increasing awareness of classroom dynamics helped her maintain discipline, and this attention enabled her to be sensitive to the students who were experiencing difficulties, and act appropriately. "I think that helped a lot, being able to be present with all of them. I picked up on some girls that really could not grasp what I was saying, and I paid a little bit more attention to them. And obviously it's all the girls that sit in the back row that don't know what's going on. But shame, one girl she really wasn't fluent in English at all, so I tried to help her. I think it helps you to become aware of different learners' needs, who needs more and others need less, not categorizing them at the same level, understanding that they need different things, if you can give it to them, of course."

During her second teaching experience, Emelda felt trusted by her colleagues, which resulted in altruistic behaviour. "I enjoyed TE because there were times when they were really understaffed and they needed things, and you could just get in and do them." At exam time, "People took the piles of papers they were supposed to invigilate and there was one left ... so I volunteered myself. I saw that actually you can be hands on, I did it without a problem." With the students, she realized that compassion sometimes needs to be firm, "In this school you have to be a bit tougher, have a tougher skin, but not avoid, especially when they say provocative stuff, you don't avoid it, you don't ignore it, you answer them in a way that gets them to realize that you are not scared of them, you are actually there to engage with them."

She offered extra lessons to a group of four disruptive students, as she realized that they did not understand certain mathematical concepts. She noticed how the lack of compassion from their normal teacher impaired their learning: "She is very impatient with them and she is 
very aggressive, so they blurt out answers in the fear that she is going to punish them, and they blurt out wrong answers and then she punishes them anyway. I got to see that actually they are children and they were not being rowdy because they are mean, it is their energy, and their energy is disruptive in class. But this time ... because they understood and they came on their own accord, it was just brilliant. It was the best thing ever for the whole TE." "I remember it so well and I walked away feeling like I did something, I actually achieved something."

In her personal life, too, she found a significant change after the compassion practices, "Definitely it has an impact on the people that I deal with, but in terms of the circumstances, not really, but then my approach to circumstances has changed." In her first interview she had spoken about conflicts with her husband, as he did not want her to be a teacher, but this had shifted over the months, and through the practices, “... the conflicts that I would have with my husband ... I calm down and I walk away from the situation, even if I am being provoked. There are times where I see that was a provocation, and I am able to stop the reaction. I accept that it is making me feel sad, and that's ok, but whatever the accusation was, I am not that person, and this is temporary and is all going to pass. I think that's very helpful."

Bonolo discussed the concept of Ubuntu, and his understanding that African cultures are based on kindness and compassion towards those less fortunate, which supports the cultural expectation to help others. He enjoyed sharing his resources where he could. The compassion practices did not seem to alter his behaviour, but rather validated his personal experience that helping others and being kind also allowed him to feel happy.

\section{DISCUSSION}

The findings were sub-divided into three areas where training in compassion appeared to be beneficial: self-compassion, empathy for the difficulties of others and altruistic behaviour. Although the research method does not allow for comparison with contemplative neuroscience studies, student teacher interviews revealed that they were able to experiment with new ways of approaching situations and difficulties after the compassion-based MBI.

The wish to help others is often a motivating factor in becoming a teacher, yet this can pose problems of sustainability, if not balanced with self-care. Turning compassion towards themselves was perceived as much more challenging than towards others, particularly for those who reported feelings of guilt, shame or perfectionism. These findings support Neff's work, which has shown that self-compassion is often rejected initially as participants fear that it will lead to complacency. However, once taught how to be self-compassionate, they reported a shift from over-identification of personal challenges to a more mindful awareness of life's difficulties; a feeling of common humanity; and a transition from a self-critical response to one 
of self-kindness. In addition, participants found that practising with a group of people that would not normally form their friendship group, allowed them to understand that all humans have emotional struggles, even if they grow up in different socio-economic circumstances.

Of note were the students who described themselves as perfectionists, driven or selfcritical (Draper-Clarke 2013). They strongly resonated with the theory and practice of selfcompassion and repeatedly referred to how these practices had supported them in their own self-care, and how that had a beneficial effect on the people around them, as they projected less of their inner conflicts onto the outside world. Georgia, for example, explored how her commitment not to criticise herself had allowed her to work at a more sustainable pace, providing moments of self-care to balance out the pressures of academic work. She also noticed how when she stepped back from over-identification, when she stopped seeing everything as "about me", she was able to touch on the problems that others experienced too, and was more mindful of their difficulties. She was not someone who isolated herself, often seeking support for her difficulties within her social group and supportive family, but now she was able to play a reciprocal role for others, not simply expecting that others should listen to her problems, but that she could also provide a holding space for friends and family members to share their concerns, without feeling the need to provide a solution.

The philosophy of Ubuntu, which several of the black participants referred to, sometimes seemed to pose initial challenges to self-compassion, yet supported compassion for others. For white students, experiences of shame and guilt as a result of their white privilege also seemed to militate against self-compassion.

In Western contexts, where much of the secular mindfulness literature has originated, stressors are predominantly internal, relating more to personality characteristics and the tendency towards mental proliferation. In such circumstances, an acceptance of involuntarily arising thoughts can be enough to alter the experiences and bring awareness to habitual tendencies that lead to suffering. In the South African context, where the threat system is triggered for many students on a daily basis (Draper-Clarke and Edwards 2016), by external circumstances (such as crime and financial concerns), the understanding that they could be kind to themselves, and that things were impermanent seemed to allow them to stay present to the difficulties, thus developing greater resilience, yet also allowed them to make clear choices in terms of how to protect themselves from danger.

The contrast between empathy and compassion was revealed in student teacher feedback. In terms of sensitivity towards the difficulties of others, there was only one student, Imogen, who noticed the potentially overwhelming result of empathy, and pointed to the dangers of empathy fatigue. She talked about her heightened awareness of people asking for money at the 
traffic lights, and was aware that practices which develop empathy can open practitioners to previously suppressed emotions, feelings of overwhelm and a tendency to shut down, if not balanced with compassionate engagement. Compassion contains a sense of agency, a willingness and ability to do something about the suffering of oneself or another. It is a prosocial quality, which was protective in allowing the student teachers to feel less overwhelmed in the face of harsh external realities. Luthuli's story of the student whose parents has been murdered revealed how he felt able to provide support, without being overwhelmed by his own sadness for the child. Providing compassionate presence for the child's suffering was enough to sustain Luthuli himself and gave him a sense of meaning and affiliation, as described in the study of Klimecki et al. (2012). For the other students, their increasing levels of sensitivity and empathy seemed to allow them to take the difficulties of others into account, so that they did not always take things so personally.

Feeling compassion towards others was quite natural for many of the students, and could be why they had chosen to enter the teaching profession in the first place. Interestingly, though, two of the black students felt that it was job security that took them into the field, rather than altruism, which they felt was a motivator for the white students only. This generalization was not borne out in the study, with both black and white students expressing their desire to help children, and improve the education system in South Africa. Weng et al. (2013) predicted that compassion training could benefit fields that depend on altruism and cooperation, particularly the human service professions such as teaching, healthcare or social work. Matching both the desirability of being involved in social change, and the sense of efficacy, or feasibility, would also benefit students considering social entrepreneurship (Urban and Kujinga 2017). This claim was supported by Atandwa, Luthuli and Emelda's descriptions of their altruistic acts. However, the design of this study relied on self-reported incidents of altruism, rather than second person reports, so it is not possible to claim that it was the compassion practices alone that led to the compassionate treatment of others. However, the practices did seem to raise awareness of the benefits of compassion, which were therefore noticed and discussed during the interviews.

With the growing understanding from neuroscience research that the brains of two people are able to exchange energy and information (Neff 2015; Siegel 2010), human service professionals can gain a deeper trust that creating a safe and supportive environment for victims of trauma does indeed allow them to integrate the experiences and re-programme the hippocampus in terms of memory, thus allowing healing. Many students coming into schools, particularly township schools, have witnessed traumatic incidents in their young lives. Teachers may not be in a position to address these external circumstances, but by creating safe havens, they are supporting children at a neurological, emotional and physiological level. 
While the face-to-face teaching of mindfulness and compassion practices is ideal, it is the regular commitment to doing these short practices that rewires the brain, and a great deal of support is now available online, or through meditation apps such as Insight Timer. Drama for Life, at Wits, is offering weekly Staff Reflexive Sessions, where mindfulness and compassion practices are facilitated, as well as integrating this material into the postgraduate curriculum. Higher education institutions are in a good position to offer this training, as they have more flexibility over their curricula, and can also conduct research on the effectiveness of the training. Research in the United States has indicated its success in addressing cognitive and academic performance, mental health and psychological well-being, as well as development of the whole person (Shapiro, Brown and Astin 2011).

\section{CONCLUSION}

The purpose of this article was to extract reported experiences of student teachers taking a compassion-based MBI and interpret their voices in light of the current literature. In addition, their voices offer suggestions for teacher education and higher education in South Africa, where there are widespread mental health challenges that need to be addressed (Waltham 2017). The clinically high levels of stress in Gauteng and harsh realities of teaching in some South African schools also need urgent attention (Draper-Clarke 2013).

Findings in this article can be summarised into six compassion-related themes: 1) The compassion-based MBI alleviated their personal difficulties and improved their sense of wellbeing; 2) They developed an increased commitment to self-care; and 3) reduced self-criticism; 4) Some students with ruminating minds experienced a reduction in mental proliferation; while 5) many discussed an increased sensitivity to the suffering of others, and 6) the altruistic motivation to help others, without becoming overwhelmed. These acts of kindness and compassion allowed them to experience for themselves that focusing on the needs of others also brought happiness to the giver. These findings challenge recent criticisms of contemporary mindfulness, which are concerned about individualism and lack of engagement with wider social issues.

I have argued that the transfer of MBIs into the South African context needs to be cognizant of the wider social and economic realities of this country in transition. South African student teachers experience both internal (stress, trauma, guilt, perfectionism) and external struggles (financial stressors, school-based issues), and need skills to address them effectively. Compassion training gives people the confidence to approach difficulties in a way that accepts the reality of the situation and informs skilful engagement. Acceptance means that the whole issue can be viewed with clarity, and teachers can learn to approach, rather than to avoid suffering, which allows for engagement in pro-social behaviour. This engagement can take the 
form of individual actions, or social activism, depending on the circumstances. Within a context of poverty, trauma and violence, compassion for self and others is critical, as well as sustained engagement, a secular or faith-based ethic of care rather than individualism, and skilful ways to address inequalities. For mindfulness to fulfil its potential, compassion practices need to be integrated to allow the development of psychological resilience in teachers so they can cope in these challenging social conditions.

The South African mindfulness community has a responsibility to contextualize the programmes taught within a society of such great inequality, and to make them widely accessible. This article adds weight to the current debate within the mindfulness literature, confirming that the inclusion of specific practices to enhance compassion may, indeed, be the more significant mediator of healing than mindfulness alone (Neff and Germer 2013). The findings support the explicit inclusion of compassion practices in MBIs, rather than relying on the embodiment of compassion within the facilitator.

The importance of teaching caregivers to care for themselves in order to reduce burnout, empathy fatigue and departure from the profession cannot be underestimated. South Africa is already severely short of skilled teachers and healthcare professionals, and must support them. This in turn will allow help to reach their clients. In education, mindfulness with compassion has the potential to improve the well-being of school teachers, and enable them to develop mindful and compassionate classrooms where pupils feel safe and can learn more effectively, whatever their home circumstances. This applies equally to lecturers, and higher education students. In a country where there is such a heightened level of fear and lack of personal safety, if educators are able to create safe environments for their learners, then this is a goal worth pursuing.

I shall close with the words of Emelda, who found great satisfaction in her role as a teacher. Her compassionate caregiving did not drain her, but rather allowed her to connect with a significant sense of worth and well-being:

"The best comment I got from my lecturer [was that] she said I provided a safe, nurturing learning environment. That, for me, was a big happy moment."

\section{REFERENCES}

Allione T. 2008. Feeding your demons: Ancient wisdom for resolving inner conflict. Little, Brown.

Armstrong, K. 2011. Twelve steps to a compassionate life. Random House.

Berceli, D. and M. Napoli. 2007. A proposal for a mindfulness-based trauma prevention program for social work professionals. Complementary Health Practice Review 11(3): 153-165. doi: $10.1177 / 1533210106297989$.

Black, D. S. 2013. Mindfulness publications by year, 1980-2012. Mindfulness Research Guide. www.mindfulexperience.org 
Brach, T. 2013. True refuge. Tantor Media, Incorporated.

Brown, K. W. and R. M. Ryan. 2003. The benefits of being present: Mindfulness and its role in psychological wellbeing. Journal of Personality and Social Psychology 84: 822-848.

Chödrön P. 2001. Tonglen: The path of transformation, ed. T. Ötro. Vajradhatu Publications.

Condon, P., G. Desbordes, W. B. Miller and D. DeSteno. 2013. Meditation increases compassionate responses to suffering. Psychological Science 24(10): 2125-2127.

Crain, T. L., K. A. Schonert-Reichl and R. W. Roeser. 2016. Cultivating teacher mindfulness: Effects of a randomized controlled trial on work, home, and sleep outcomes. Journal of Occupational Health Psychology. doi: 10.1037/ocp0000043.

Davidson, R. J. and A. Harrington. 2002. A science of compassion or a compassionate science? What do we expect from a cross-cultural dialogue with Buddhism? In Visions of compassion: Western scientists and Tibetan Buddhists examine human nature, ed. A. Harrington. New York: Oxford University Press.

Department of Education. 2005. A National Framework for Teacher Education in South Africa. 16 June, Pretoria.

Department of Education. 2007. The National Policy Framework for Teacher Education and Development in South Africa, Pretoria. Government Gazette, Vol. 502, No. 29832.

Desbordes, G., T. Gard, E. A. Hoge, B. K. Hölzel, C. Kerr, S. W. Lazar, A. Olendzki and D. R. Vago. 2015. Moving beyond mindfulness: Defining equanimity as an outcome measure in meditation and contemplative research. Mindfulness 6(2): 356-372.

DoE see Department of Education.

Draper-Clarke, L. J. 2013. Evaluation of a mindfulness training programme for student teachers: Implications for its potential to enhance well-being and support teacher education. In SAERA 2013 Conference Proceedings: Educational Research in South Africa: Practices and Perspectives, ed. F. E. Gouws and C. C. Wolhuter. Cape Town: Oxford University Press.

Draper-Clarke, L. J. and D. E. Edwards. 2016. Stress and coping among student teachers at a South African University: An exploratory study. Journal of Psychology in Africa 26(6): 491-499.

Feldman, C. and W. Kuyken. 2013. Mindfulness: Diverse perspectives on its meaning, origins and applications, ed. J. M. G. Williams and J. Kabat-Zinn. Routledge.

Gilbert, P. 2010. The compassionate mind: A new approach to life's challenges. New Harbinger Publications.

Gilbert, P. and Choden. 2013. Mindful compassion. Constable \& Robinson Ltd.

Gilbert, P. and S. Procter. 2006. Compassionate mind training for people with high shame and selfcriticism: Overview and pilot study of a group therapy approach. Clinical Psychology \& Psychotherapy 13(6): 353-379.

Gilbert, P. and D. Tirch. 2009. Emotional memory, mindfulness and compassion. In Clinical handbook of mindfulness, 99-110. Springer New York.

Goetz, J. L., D. Keltner and E. Simon-Thomas. 2010. Compassion: An evolutionary analysis and empirical review. Psychological Bulletin 136(3): 351.

Greeson, J. M. 2009. Mindfulness research update: 2008. Complementary health practice review.

Groothuis, D. 2004. Dangerous meditations. http://www.christianitytoday.com/ct/2004/november/ 10.78.html

Gyatso, T. (H.H. the XIV Dalai Lama). 2001a. An open heart: Practising compassion in everyday life. Hachette UK.

Gyatso, T. (H.H. the XIV Dalai Lama). 2001b. Ethics for the new millenium. New York: Riverhead Trade.

Herman, A. A., D. J. Stein, S. Seedat, S. G. Heeringa, H. Moomal and D. R. Williams. 2009. The South African Stress and Health (SASH) study: 12-month and lifetime prevalence of common mental 
disorders. SAMJ: South African Medical Journal 99(5): 339-344. http://www.scielo.org.za/scielo.php?script=sci_arttext\&pid=S0256-95742009000500022\&lng= en\&tlng=pt (Accessed 31 October 2016).

Holmes, K. 2010. Samye Ling distance learning Dharma study programme. http://www.calm-andclear.eu/nangiintro.html

Jennings, P. A. and M. T. Greenberg. 2009. The prosocial classroom: Teacher social and emotional competence in relation to student and classroom outcomes. Review of Educational Research, 79(1): 491-525.

Kabat-Zinn, J. 1994. Wherever you go there you are. New York: Hyperion.

Kabat-Zinn, J. 2003. Mindfulness-based interventions in context: Past, present, and future. Clinical Psychology: Science and Practice 10(2): 144-156.

Kabat-Zinn, J. 2005. Coming to our senses: Healing ourselves and the world through mindfulness. New York: Hyperion.

Keane, M. 2017. Quiet writing: Retreat as pedagogy. South African Journal of Higher Education 31(2): 138-153. http://dx.doi.org/10.208535/31-2-1339

Klimecki, O. M., S. Leiberg, C. Lamm and T. Singer. 2012. Functional neural plasticity and associated changes in positive affect after compassion training. Cerebral Cortex, bhs142.

Kornfield, J. 2009. The wise heart: A guide to the universal teachings of Buddhist psychology. Bantam.

Kyriacou, C. 2011. Teacher stress: From prevalence to resilience. Handbook of Stress in the Occupations. Cheltenham: Edward Elgar.

Loizzo, J. 2014. Meditation research, past, present, and future: Perspectives from the Nalanda contemplative science tradition. Annals of the New York Academy of Sciences 1307(1): 43-54.

Lutz, A., J. Brefczynski-Lewis, T. Johnstone and R. J. Davidson. 2008. Regulation of the neural circuitry of emotion by compassion meditation: Effects of meditative expertise. PloS one 3(3): e1897.

Marsay, G. and C. Higson-Smith. 2005. Exploring compassion fatigue and trauma in the South African learning environment. Johannesburg: Learning and Violence.

Marx, R. 2015. Accessibility versus integrity in secular mindfulness: A Buddhist commentary. Mindfulness 6(5): 1153-1160. doi:10.1007/s12671-014-0366-3.

Meikeljohn, J., C. Phillips, M. L. Freedman, M. L. Griffin, G. Biegel, A. Roach, J. Frank, C. Burke, L. Pinger, G. Soloway, R. Isberg, E. Sibinga, L. Grossman and A. Saltzman. 2012. Integrating mindfulness training into K-12 education: Fostering the resilience of teachers and students. Mindfulness doi: 10.1007/s12671-012-0094-5.

Monteiro, L. M., R. F. Musten and J. Compson. 2015. Traditional and contemporary mindfulness: Finding the middle path in the tangle of concerns. Mindfulness 6(1): 1-13.

Nairn, R. 2009. Mindfulness: The art of being present. Rokpa Trust: Dumfries \& Galloway.

Neff, K. D. 2015. The five myths of self-compassion. Psychotherapy Networker. https://www.psychotherapynetworker.org /magazine/article/4/the-5-myths-of-self-compassion (Accessed 31 October 2016).

Neff, K. D. 2003. Self-compassion: An alternative conceptualization of a healthy attitude toward oneself. Self and Identity 2(2): 85-101.

Neff, K. D. and C. K. Germer. 2013. A pilot study and randomized controlled trial of the mindful selfcompassion program. Journal of Clinical Psychology 69(1): 28-44.

Nussbaum, M. C. 2003. Upheavals of thought: The intelligence of emotions. Cambridge University Press.

Ozawa-de Silva, B. R., B. Dodson-Lavelle, C. L. Raison, L. T. Negi, B. R. O. Silva and D. Phil. 2012. Compassion and ethics: Scientific and practical approaches to the cultivation of compassion as a foundation for ethical subjectivity and well-being. Journal of Healthcare, Science and the Humanities 2(1): 145-161. 
Paulse, J. 2005. Sources of occupational stress for teachers, with specific reference to the inclusive education model in the Western Cape. Doctoral dissertation, Department of Industrial Psychology, Faculty of Economic and Management Sciences, University of the Western Cape.

Purser, R. E. 2015. Clearing the muddled path of traditional and contemporary mindfulness: A response to Monteiro, Musten, and Compson. Mindfulness 6(1): 23-45. doi:10.1007/s12671-014-0373-4.

Purser, R. and D. Loy. 2013. Beyond McMindfulness. Huffington post 1(7): 13.

Roe-Berning, S. 2009. The complexity of posttraumatic growth: Evidence from a South African sample. Masters Dissertation, University of Witwatersrand.

Roeser, W. R., E. Skinner, J. Beers and P. A. Jennings. 2012. Mindfulness training and teachers' professional development: An emerging area of research and practice. Child Development Perspectives 6(2): 167-173.

Salzberg, S. and J. Kabat-Zinn. 2004. Loving kindness: The revolutionary art of happiness. Shambhala Publications.

Saptoe, C. W. 2000. Factors which cause stress to teachers in the South Cape. Unpublished Masters dissertation. Port Elizabeth: University of Port Elizabeth.

Seppala, E., T. Rossomando and J. R. Doty. 2013. Social connection and compassion: Important predictors of health and well-being. Social Research: An International Quarterly 80(2): 411-430.

Shapiro, S. L., K. W. Brown and J. Astin. 2011. Toward the integration of meditation into higher education: A review of research evidence. Teachers College Record 113(3): 493-528.

Sharf, R. H. 2015. Is mindfulness Buddhist? (and why it matters). Transcultural Psychiatry 52(4): 470484.

Sherif, M., O. Harvey, B. White, W. Hood and C. Sherif. 1961. Intergroup conflict and cooperation: The robber's cave experiment. Norman, OK: University of Oklahoma.

Siegel, D. J. 2010. The mindful therapist: A clinician's guide to mindsight and neural integration. (Norton Series on Interpersonal Neurobiology). WW Norton \& Company.

Singer, T. and O. M. Klimecki. 2014. Empathy and compassion. Current Biology 24(18): R875-R878.

Steyn, M. G. and G. Kamper. 2006. Understanding occupational stress among educators: An overview. Africa Education Review 3(1-2): 113-133. doi: 10.1080/18146620608540446.

Strauss, C., B. L. Taylor, J. Gu, W. Kuyken, R. Baer, F. Jones and K. Cavanagh. 2016. What is compassion and how can we measure it? A review of definitions and measures. Clinical Psychology Review 47: 15-27.

Teasdale, J. D., Z. V. Segal and J. M. G. Williams. 2003. Mindfulness training and problem formulation. Clinical psychology: Science and practice 10(2): 157-160.

Urban, B. and L. Kujinga. 2017. Towards social change: South African university students as social entrepreneurs. South African Journal of Higher Education 31(1): 243-259.

Waltham, L. 2017. Mental health needs to be prioritised on our campuses. Huffington Post 14 November 2017. https://www.huffingtonpost.co.uk/luke-waltham/mental-health-needs-to-be-prioritised-onour-campuses_a_23265485/?ncid=other_saredirect_m2afnz7mbfm (Accessed 10 March 2019).

Weng, H. Y., A. S. Fox, A. J. Shackman, D. E. Stodola, J. Z. Caldwell, M. C. Olson, G. M. Rogers and R. J. Davidson. 2013. Compassion training alters altruism and neural responses to suffering. Psychological Science 24(7): 1171-1180. doi: 10.1177/0956797612469537.

Williams, S. L., D. R. Williams, D. J. Stein, S. Seedat, P. B. Jackson and H. Moomal. 2007. Multiple traumatic events and psychological distress: The South Africa stress and health study. Journal of Traumatic Stress 20(5): 845-855. doi: 10.1002/jts.20252.

Wright, R. 2010. The moral animal: Why we are, the way we are: The new science of evolutionary psychology. Vintage.

Xaba, M. I. 2003. Managing teacher turnover. South African Journal of Education 23(4): 287-291. 